\title{
Fluorescence Properties of Some Triazene Polyacrylates for Possible Sensor Applications
}

\author{
By Emil Constantin Buruiana, ${ }^{*}$ Lenuta Stroea, and Tinca BURUiana
}

\begin{abstract}
We report here a first study on the capacity of the triazene chromophore attached to a polymeric backbone to present fluorescence properties. The sensing ability of two triazene copolymers poly[1-(phenyl)-3-(2 acryloyloxyethyl)-3-methyl triazene-1-co-methyl methacrylate] (TCP-1) and poly[1-(paramethoxy-phenyl)-3-(2 acryloyloxyethyl)-3-methyl triazene-1co-methyl methacrylate] (TCP-2) in dimethylformamide (DMF) has been investigated by fluorescence spectroscopy in tandem with a quenching experiments using a variety of metal ions $\left(\mathrm{Fe}^{3+}, \mathrm{Fe}^{2}, \mathrm{Cu}^{2+}\right.$ and $\left.\mathrm{Cu}^{+}\right)$, which suggests that these triazene polymers could find practical applications for detection of metal ions. The emission spectra exhibited strong fluorescence emissions at $375 \mathrm{~nm}$ (TCP-1) and $410 \mathrm{~nm}$ (TCP-2) respectively, while the ability of $\mathrm{Fe}^{3+}, \mathrm{Fe}^{2+}, \mathrm{Cu}^{2+}$ and $\mathrm{Cu}^{+}$ to quench the fluorescence of the triazene fluorophore has been explained on the basis of energy transfer processes involving the triazene excited state and the metal ion. The corresponding Stern-Volmer representations for all fluorescence emission spectra were also described.
\end{abstract}

KEY WORDS: Polyacrylates / Fluorescence / Quenching / Sensor /

Fluorescence spectroscopy and its applications in biochemical, medical, and chemical research have improved rapidly during the past decade. ${ }^{1}$ The increased interest on fluorescence emission appears to be the consequence of numerous developments and the fast appearance of new fluorescence methods in explaining physical and life sciences research. Based on sensitivity, selectivity and non-destructive characteristics, fluorescence spectroscopy can evidence various photophysical properties like fluorescence intensity, ${ }^{1}$ emission maximum, ${ }^{2}$ anisotropy, excimer or exciplex formation, ${ }^{3}$ etc., whereas any variation caused by connecting or interacting with special external species (for instance, metal ions) could be used for sensing purposes. ${ }^{4}$ In fact, the fluorescent sensors can offer several distinct advantages in terms of sensitivity, selectivity, response time and local observation. In the case of selective fluorescence sensors for cation detection, the scientists made considerable efforts for the development of these kinds of systems.

As a general characteristic, fluorescence quenching refers to any process which undergoes emission intensity changes of a given molecule. Fluorescence response can be generated by a variety of mechanisms, including excited state reactions, energy transfer, complex formation, and collision quenching, 5,6 while photoinduced electron transfer and electronic energy transfer are considered the two main deactivation pathway responsible for an efficient fluorescence inhibition.

Our group has specially focused on designing and fabricating a diversity of (co)polymers bearing different fluorophores such as pyrene, ${ }^{7,8}$ dansyl, ${ }^{9}$ stilbene ${ }^{10,11}$ or anthracene ${ }^{12}$ characterized through high quantum yields and good extinction coefficients, making them attractive components of biological and chemical sensors.
Recently, the polymeric systems with light controlled surface topology have been intensively explored due to their unique properties that allow various applications as photoresponsive materials ${ }^{13}$ for medical purpose ${ }^{14}$ and optical data storage $^{15}$ area. In this context, promising candidates to accomplish all targets are polymers with triazene moieties ( $>N-N=N-$ ), whose biological activity was successfully tested in cancer therapy, ${ }^{14}$ and which have gained importance as useful tools in organic synthesis ${ }^{15}$ or in processes following the laser structuring compared to the UV-light. ${ }^{16-18}$

Taking in consideration the special properties of triazene compounds and our interest in developing photopolymers including triazene polyacrylates, ${ }^{19,20}$ here we report a first study on the ability of the triazene copolymers to present fluorescence properties. Also, significant arguments about physical and chemical aspects of triazene moieties will be presented, because these investigations can offer essential information in understanding the mechanism of fluorescence. Moreover, the interaction between triazene copolymers and some metal cations $\left(\mathrm{Fe}^{3+}, \mathrm{Fe}^{2+}, \mathrm{Cu}^{2+}\right.$ and $\left.\mathrm{Cu}^{+}\right)$can cause the quenching of fluorescence intensity, property exploitable in the field of chemical sensors.

\section{EXPERIMENTAL}

\section{Synthesis of Triazene Acrylic Copolymers}

Detailed synthesis of triazene copolyacrylates are presented in our previously research papers. ${ }^{19,20}$ Generally, the preparation of triazene acrylic copolymers poly[1-(phenyl)-3-(2 acryloyloxyethyl)-3-methyl triazene-1-co-methyl methacrylate] (TCP-1) and poly[1-(para methoxy-phenyl)-3-(2 acryloyloxyethyl)-3-methyl triazene-1-co-methyl methacrylate] 


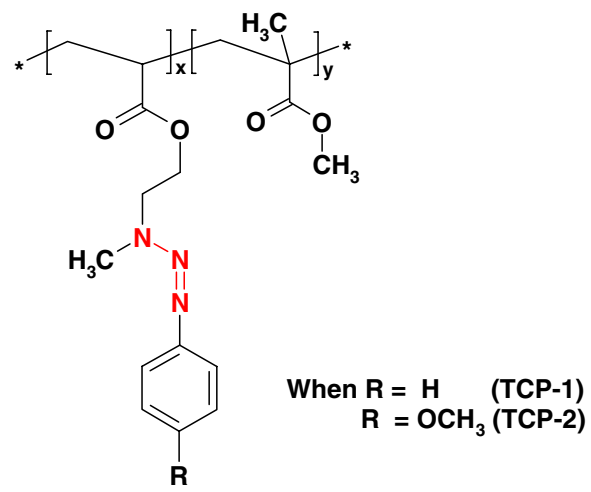

Scheme 1. General chemical structure of the triazene acrylic copolymers TCP-1 and TCP-2.

(TCP-2) (Scheme 1) was performed as a free-radical polymerization in dioxane using $0.2 \% \mathrm{AIBN}$ as initiator. The reaction mixture was kept in sealed glass ampoules at $60^{\circ} \mathrm{C}$ for $3 \mathrm{~h}$ and the resulting polymer were precipitated in methanol and dried for $48 \mathrm{~h}$ under reduced pressure.

TCP-1. $\quad M_{\mathrm{w}}$ (determined by GPC): 193,$400 ; M_{\mathrm{w}} / M_{\mathrm{n}}=1.9$. ${ }^{1} \mathrm{H}$ NMR (DMSO- $\left.d_{6}, \delta, \mathrm{ppm}\right): 7.1-7.4$ (aromatic protons), 3.69-4.3 $\left(\mathrm{CH}_{2}-\mathrm{CH}_{2}\right), 3.58\left(-\mathrm{COOCH}_{3}\right), 3.29-3.37\left(\mathrm{~N}-\mathrm{CH}_{3}\right)$, 1.5-2.2, $\left(\mathrm{CH}-\mathrm{COOCH}_{3}\right), 0.8-1.5\left(\mathrm{CH}_{2}\right.$ and $\mathrm{CH}_{3}$ from acrylic backbone). Molar fraction of triazene monomer in copolymer (determined by NMR analysis): 0.24 .

TCP-2. $\quad M_{\mathrm{w}}$ (determined by GPC): 85,$000 ; M_{\mathrm{w}} / M_{\mathrm{n}}=1.8$. ${ }^{1} \mathrm{H}$ NMR (DMSO- $\left.d_{6}, \delta, \mathrm{ppm}\right)$ : 7.30-6.9 (aromatic protons), 4.14-3.75 $\left(\mathrm{CH}_{2}-\mathrm{CH}_{2}\right), 3.70\left(\mathrm{O}-\mathrm{CH}_{3}\right) 3.54\left(-\mathrm{COOCH}_{3}\right), 3.17$ (N-CH 3$), 2.1-1.4$ (CH-COO-), 1.35-0.74 $\left(\mathrm{CH}_{2}\right.$ and $\mathrm{CH}_{3}$ from acrylic backbone). Molar fraction of triazene monomer in copolymer: 0.16 .

\section{Materials}

All chemicals (Aldrich) were used as received without purifications. Only dimethylformamide (DMF) wad dried over $5 \AA$ molecular sieves.

\section{Instruments}

The structure of acrylic copolymers was verified by ${ }^{1} \mathrm{H}$ NMR and FT-IR spectroscopy using a Bruker $400 \mathrm{MHz}$ spectrometer and a Bruker Vertex 70 spectrophotometer, respectively. For UV investigations, the samples were exposed to UV irradiation using a $500 \mathrm{~W}$ high-pressure mercury lamp without wavelength selection, at room temperature. The fluorescence spectra were recorded with an SLM 8000 spectrofluorimeter (Japan) and the quenching study was carried out using different transition metal ions.

\section{RESULTS AND DISCUSSION}

In our recent communications ${ }^{19,20}$ we have reported a series of novel polyacrylates with triazene units in the side chain tailored for microlithography ${ }^{21}$ and photoresist technique, ${ }^{22}$ owing to specific behavior of photoclivable triazene chromophore capable to undergo a photochemical decomposition with
Table I UV-vis spectral characteristics of triazene copolymers TCP-1 and TCP-2

\begin{tabular}{ccc}
\hline Copolyacrylates & UV-vis absorption maxima $(\mathrm{nm})$ & Rate constants $\left(\mathrm{s}^{-1}\right)$ \\
\hline TCP-1 & $286,320(\mathrm{DMF})$ & $8 \times 10^{-3}$ \\
TCP-2 & 290,330 (DMF) & $2.3 \times 10^{-3}$ \\
\hline
\end{tabular}

release of molecular nitrogen. In order to connect the photochemical data with photophysical ones, the photodecomposition of the synthesized copolyacrylates (TCP-1 and TCP-2) was monitored by UV spectroscopy during irradiation performed with a high-pressure mercury lamp. For both copolymers, UV-vis spectra are similar and show strong absorption bands (Table I) attributed to $\pi-\pi^{*}$ transition of the triazene unit. Thus, upon their exposure to UV irradiation, the absorption maxima measurements confirm the progressive decomposition of the triazene chromophore and its exhaustive irradiation cause the disappearance of all the absorption bands, proving in this way an irreversible cleavage of triazene moieties attached to the polymeric backbone. Moreover, the kinetic evaluation of the process can be expressed by a firstorder rate equation using the equation:

$$
\ln \frac{A_{0}}{A_{t}}=k t
$$

where $A_{0}$ and $A_{t}$ are the values of the absorbance at times $t_{0}$ and $t$, respectively, and $k$ is a rate constant. Accordingly, the $\mathrm{k}$ value calculated for the phenyl- and respectively, methoxyphenyl triazene copolyacrylates (TCP-1 and TCP-2) are presented in Table I, too.

Having established that the triazene chromophores can be photodecomposed in DMF, we next proposed a possible decomposition scheme for the synthesized triazene polyacrylates (Scheme 2). In the first step, we suppose a trans-cis photoisomerization of the $N=N$ bond with the formation of the cis isomer, thermodynamically instable. However, UV irradiation cleaves this link releasing a molecule of molecular nitrogen and generating others active macroradicals, including phenyl/methoxy-phenyl diazenyl ones. All these species appeared in system can be stabilized by hydrogen extraction or recombination, with the mention that there is a possibility that the latter one be capable to form fluorescent products.

Arguments in favor of the above mentioned assumption can be obtained by irradiation of the TCP-1 solution in DMF up to the disappearance of the absorption band of triazene unit in the corresponding UV-vis spectrum (Figure 1).

Indeed, after $10 \mathrm{~min}$ of irradiation with a high pressure mercury lamp, the absorption maxima located at $286 \mathrm{~nm}$ and $320 \mathrm{~nm}$ disappeared completed, sustaining thus the irreversible decomposition of the triazene units from copolymer. Under these circumstances, using an excitation wavelength of $\lambda_{\mathrm{exc}}=320 \mathrm{~nm}$ and measuring the fluorescence emission, we see that the TCP-1 solution exhibited a broad emission band centered at $375 \mathrm{~nm}$. Figure 2 illustrates the effect of UVirradiation on the emission spectrum of TCP-1 solution that agrees almost perfectly with our prediction. 

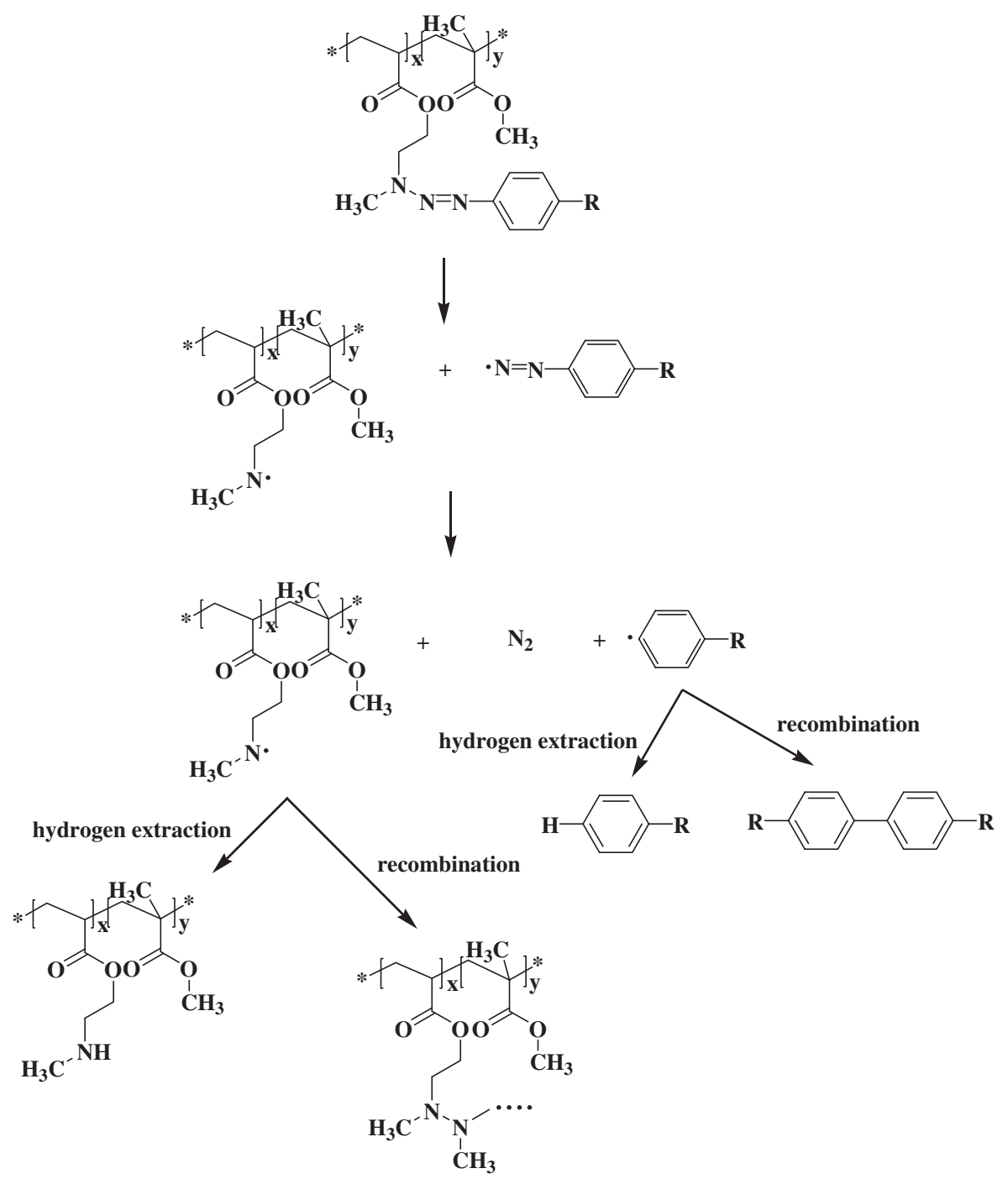

Scheme 2. A possible decomposition scheme for triazene based polyacrylates.

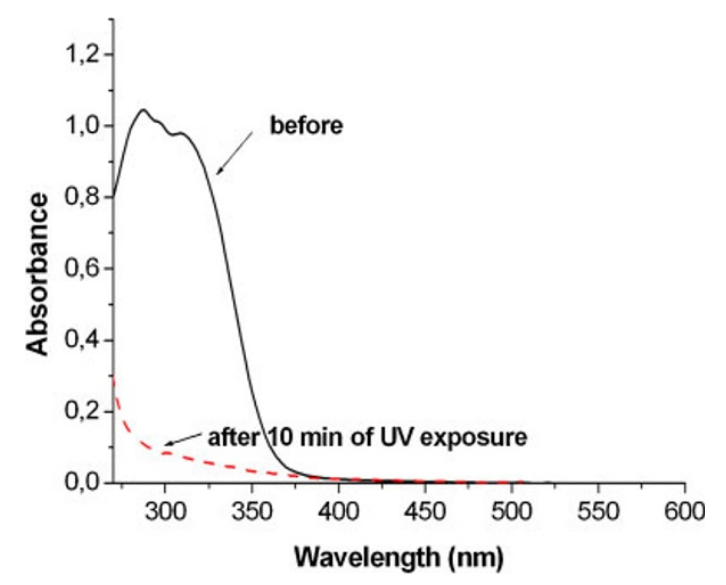

Figure 1. UV-vis absorption spectra for TCP-1 in DMF solution before and after 10 min of UV irradiation.

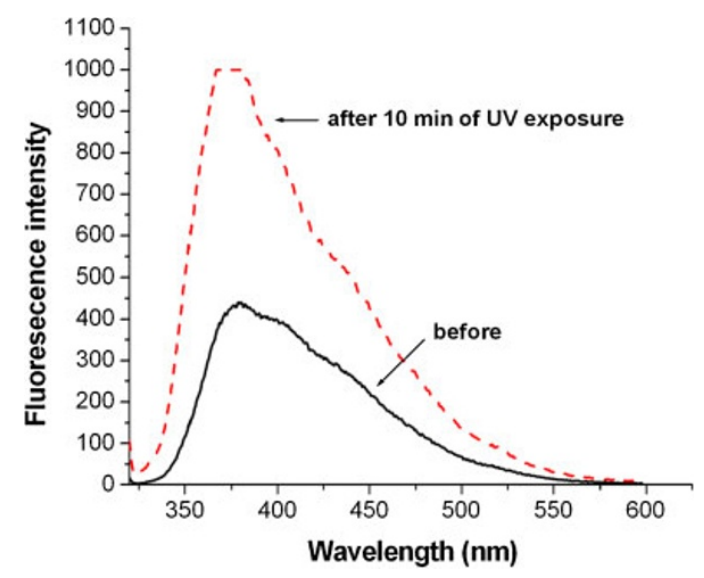

Figure 2. The fluorescence excitation spectra of TCP-1 in DMF before and after $10 \mathrm{~min}$ of UV irradiation $\left(\lambda_{\mathrm{exc}}=320 \mathrm{~nm}\right)$. 
On the other hand, an increase in the fluorescence intensity of about 3 times after $10 \mathrm{~min}$ irradiation of the polymer solution suggested us that the products formed through a recombination of diazenyl radicals emits fluorescence with a high quantum yield. From this experiment, it was clearly established that the triazene moiety $(>N-N=N-)$ is responsible of emission maximum, and that, furthermore, the main photodecomposition products may lead to fluorescence structures with quantum yields significantly higher than of the starting polymer solution.

In a further demonstration of this behavior, we experimentally measured photoresponse in the TCP-1 film exposed under identical conditions (not evidenced here). Consequently, it was found that the effect of irradiation on the fluorescence maximum was reflected in a bathochromic shift with about $25 \mathrm{~nm}$, which indicates the formation of aggregates in the polymeric film. Given these observations, we can conclude that the triazene polyacrylates are the first pattern of such polymers which exhibit emissive properties either in solution or film state, and hence they could play an important role in other applications. Additionally, the effect of varying irradiation time sustained that the irreversible decomposition of the triazene units is always accompanied of photocrosslinking of the polymeric film, as resulted from the solubility data of the irradiated area (developed in $\mathrm{CHCl}_{3}$ ), which in turn decrease with increasing irradiation time (up to $2 \mathrm{~h}$ ).

In order to obtain more information about microenvironment of the triazene fluorophore, we report here the influence of different metal ions $\left(\mathrm{Fe}^{3+}, \mathrm{Fe}^{2+}, \mathrm{Cu}^{2+}\right.$ and $\left.\mathrm{Cu}^{+}\right)$on the emission intensity of TCP-1 and TCP-2 triazene copolyacrylates in DMF solution. To our best knowledge, this is a first example of fluorescent chemosensor for detecting various metal ions of environmental and biological interest using triazene polymers, as soon as their fluorescence is quenched completely or red/blue-shifted by the addition of metal ions, depending on the kind of metal ion. Keeping this in mind and in continuation of our studies on triazene polymers we measured the emission spectra of TCP-1 in DMF, excited by $320 \mathrm{~nm}$. The changes in the fluorescence decay behavior of TCP-1 on the addition of the $\mathrm{FeSO}_{4}\left(\mathrm{Fe}^{2+}\right.$ ions) are displayed in Figure 3.

It can be seen that with the addition of $\mathrm{Fe}^{2+}$ ions, the fluorescence intensity from $375 \mathrm{~nm}$ is found to disappear gradually, so that at a certain concentration of $1.6 \times 10^{-4} \mathrm{M}$ $\mathrm{FeSO}_{4}$ the fluorescence decay is about $38 \%$. Also, it is important to be noted that the minimum quencher concentration detected in the system is $0.16 \times 10^{-4} \mathrm{M}$.

In a similar manner, the emission intensity of TCP-2 copolymer decreased at the beginning when the concentration of the quencher was $0.1 \times 10^{-4} \mathrm{M}$ (Figure 4 ), whereas a degree of quenching of $36 \%$ was determined for a concentration of $1.6 \times 10^{-4} \mathrm{M} \mathrm{FeSO}_{4}$. The observed quenching efficiencies of the $\mathrm{Fe}^{2+}$ ions are found to be quite similar for both system, with a small improvement of about $2 \%$ for TCP-1 $(38 \%)$ compared to TCP-2 $(36 \%)$ at the same quencher concentration $\left(1.6 \times 10^{-4} \mathrm{M}\right)$.

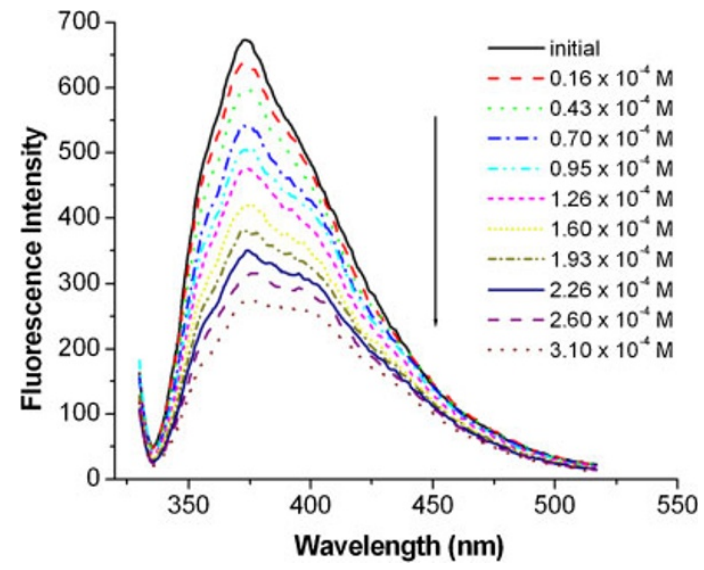

Figure 3. Emission spectra changes recorded for TCP-1 in DMF after addition of $\mathrm{Fe}^{2+}$ metal ions.

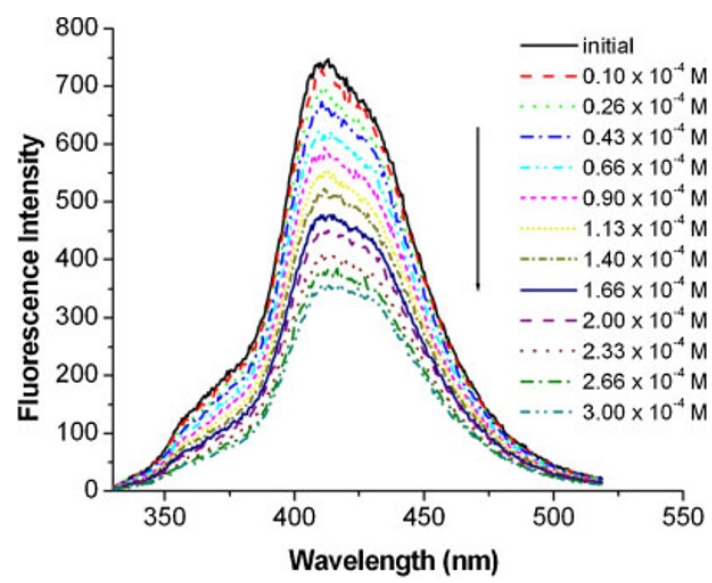

Figure 4. Effect of $\mathrm{FeSO}_{4}$ quencher on the fluorescence intensity of 1-(para methoxy-phenyl)-3-(2 acryloyloxyethyl)-3-methyl triazene-1-comethyl methacrylate (TCP-2) in DMF.

In parallel, for $\mathrm{FeCl}_{3}$ used as quencher the same course of action was observed, so that at a concentration of $1.0 \times 10^{-4} \mathrm{M}$ $\mathrm{FeCl}_{3}$ the emission decay is about $40 \%$. Moreover, the changes in the fluorescence decay behavior of TCP-2 on the addition of the $\mathrm{FeCl}_{3}\left(\mathrm{Fe}^{3+}\right.$ ions) determined a higher degree of quenching (48\%) for the concentration of $1.0 \times 10^{-4} \mathrm{M} \mathrm{FeCl}_{3}$. Here the fluorescence maximum corresponding to TCP-2 copolymer decreased for the first time, when the concentration of the quencher was $0.2 \times 10^{-4} \mathrm{M}$, also (as we will see later).

When metal quenchers, like $\mathrm{Cu}^{2+}$ and $\mathrm{Cu}^{+}$were added to triazene copolyacrylates solution, very sensitive fluorescence quenching occurred even at very low concentrations of ions. Furthermore, $\mathrm{Cu}^{2+}$ can be considered an excellent quencher for the triazene chromophore because it is a good electron scavenger as a consequence of its electronic structure $\left(d^{9}\right),{ }^{23,24}$ inducing accessible low energy levels to excited states of the molecules.

For example, if $\left(\mathrm{CH}_{3} \mathrm{COO}\right)_{2} \mathrm{Cu}$ was added to the TCP-1 and TCP-2 solutions, the strong emission bands around $375 \mathrm{~nm}$ and $410 \mathrm{~nm}$ respectively, moved bathochromically towards a longer 


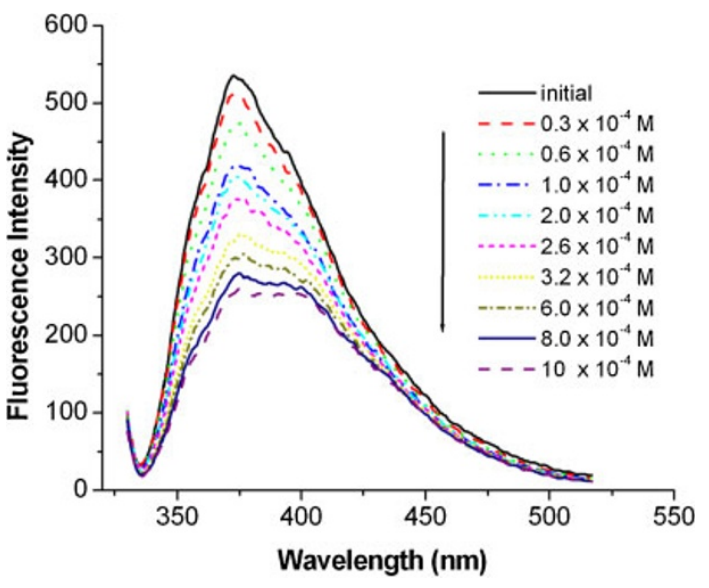

Figure 5. Changes in the fluorescence spectra of TCP-1 solution in DMF by the addition of $\left(\mathrm{CH}_{3} \mathrm{COO}\right)_{2} \mathrm{Cu}$.

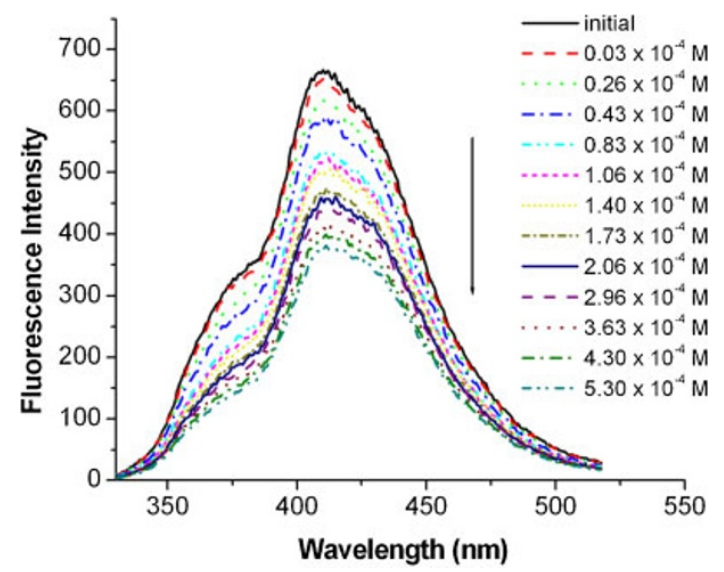

Figure 6. The fluorescence spectra of TCP-2 solution in DMF in the presence of $\left(\mathrm{CH}_{3} \mathrm{COO}\right)_{2} \mathrm{Cu}$.

wavelength $(\sim 2 \mathrm{~nm})$ with a gradual decrease in fluorescence intensity (Figures 5 and 6). In addition, in the case of phenyl triazene copolymer (TCP-1) a small emission band grew around $400 \mathrm{~nm}$.

Comparing all the spectroscopic data collected at the same quencher concentration $\left(2.0 \times 10^{-4} \mathrm{M}\right)$, it can be observe that the fluorescence quenching of $\mathrm{FeSO}_{4}$ (46\% for TCP-1 and $40 \%$ for TCP-2) is considerable more efficient than that resulted in the case of using of $\left(\mathrm{CH}_{3} \mathrm{COO}\right)_{2} \mathrm{Cu}(24 \%$ for TCP-1 and $30 \%$ for TCP-2). Such photoresponse in the above systems could be assigned to major energy transfer efficiency between the excited-states of the triazene fluorophore and transition metal ions.

The influence of $\mathrm{CuBr}_{2}$ on the emission spectra of the triazene moiety was also investigated. For TCP-1 solution (not observed here), the shape and position of the fluorescence maximum remained the same, until the detection limit of $\mathrm{Cu}^{2+}$ became $0.03 \times 10^{-4} \mathrm{M}$. From this moment, the characteristic peak decreased obviously, when the concentration of metal ions increased.

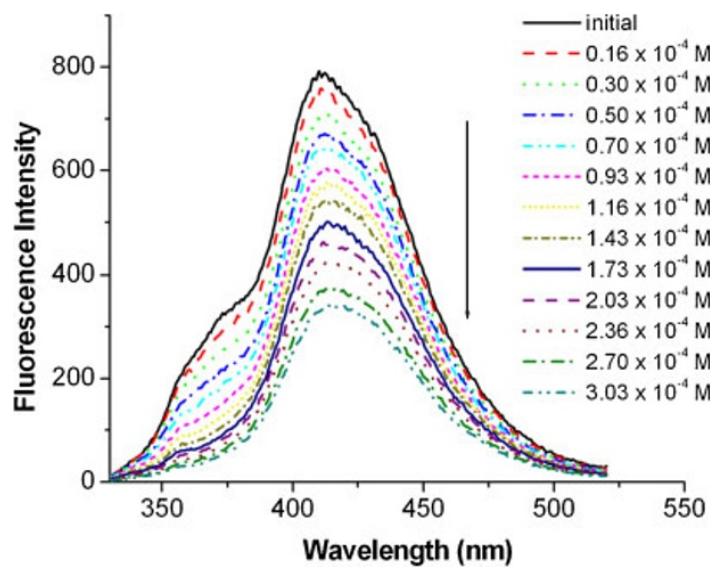

Figure 7. Emission spectra changes recorded upon addition of $\mathrm{CuBr}_{2}$ to TCP-2 solution in DMF $\left(\lambda_{\text {exc }}=320 \mathrm{~nm}\right)$.

As compared with TCP-1 polymer fluorescence spectra, for TCP-2 solution in DMF a quenching improvement was registered. The changes in emission spectra for TCP-2 by addition of $\mathrm{Cu}^{2+}$ can be seen in Figure 7. Here, a concentration of $2.03 \times 10^{-4} \mathrm{M} \mathrm{CuBr}_{2}$ causes a $42 \%$ quenching of fluorescence intensity as soon as a similar concentration for TCP-1 was generating a degree of quenching of $32.5 \%$.

For a comparison purpose, the same experiment was also conducted for the low molecular monomer (1-(phenyl)-3-(2 acryloyloxyethyl)-3-methyl triazene-1). In this case, it was found that the fluorescence efficiency of $\mathrm{CuBr}_{2}$ at the same molar concentration is lower $(10 \%)$ than that found in the above polymeric system, where there is most probably stronger interaction with the former than the latter one does. We, therefore, conclude that the polymer structure is a noticeable advantage in the fluorescence quenching phenomenon caused mainly by structural factor often named as "fluorescence structural self-quenching effect." 25

We also examined the effect of the $\mathrm{Cu}^{+}$ions on the fluorescence decay behaviour of both polymeric systems, when metal ion addition is associated with a gradual decrease in the fluorescence intensity. The changes in the fluorescence decay of TCP-1 on the addition of $\mathrm{CuCl}$ are illustrated in Figure 8 . Thus, addition of metal ions in the polymer solution systematically decreased the degree of quenching, when for a concentration of $1.6 \times 10^{-4} \mathrm{M} \mathrm{CuCl}$, its value was $36 \%$.

As can see from Figure 9, $\mathrm{CuCl}$ cause a large quenching of the triazene chromophore from TCP-2. In this case, when metal quencher $\mathrm{CuCl}$ was added to TCP-2 solution, very sensitive fluorescence quenching occurred even at very low concentration $\left(0.1 \times 10^{-4} \mathrm{M}\right)$. Correspondingly, the triazene emission was quenched by $\mathrm{CuCl}$, when the concentration of quencher was $2.3 \times 10^{-4} \mathrm{M} \mathrm{CuCl}$, the degree of quenching being of only $11 \%$.

Comparing the quenching efficiencies of the $\mathrm{Cu}^{2+}$ and $\mathrm{Cu}^{+}$ ions at the same concentration $\left(2.1 \times 10^{-4} \mathrm{M}\right)$ it was found a slight improvement for $\mathrm{Cu}^{2+}$ ions $(32.5 \%$ for TCP-1; $41 \%$ for TCP-2) than for $\mathrm{Cu}^{+}$ions (15\% for TCP-1 and respectively, $11 \%$ for TCP-2). 


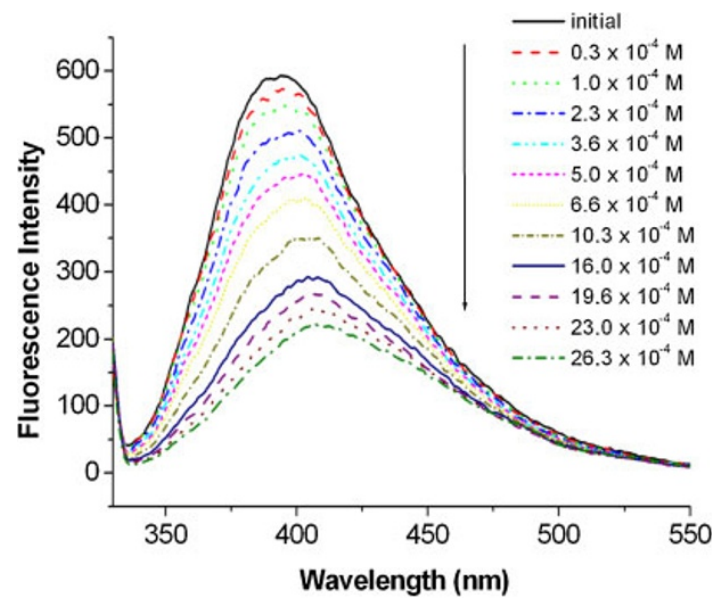

Figure 8. Fluorescence emission spectra of the TCP-1 solution in DMF as a function of $\mathrm{CuCl}$ concentration.

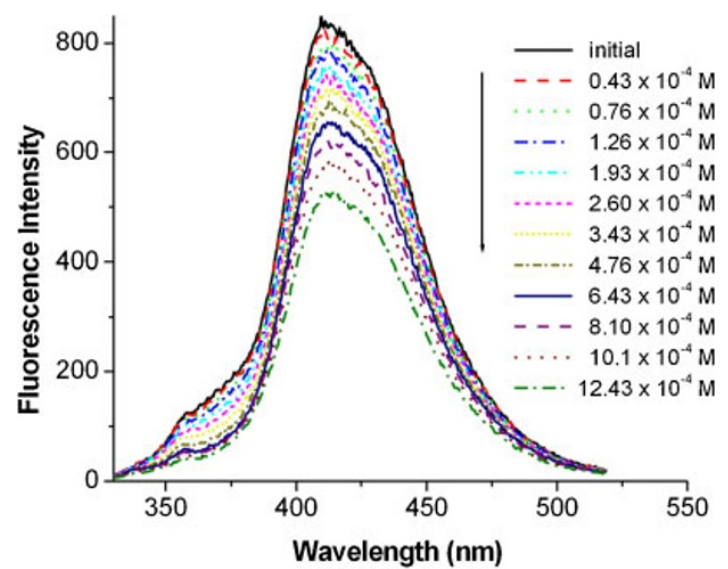

Figure 9. Emission spectra changes evidenced upon addition of $\mathrm{CuCl}$ to TCP-2 solution in DMF $\left(\lambda_{\mathrm{exc}}=320 \mathrm{~nm}\right)$.

Interestingly, however, the fluorescence maxima of both triazene copolyacrylates in the presence of quenchers are slightly red-shifted with respect to the initial maxima in DMF. The bathochromic shift (by $c c a 10 \mathrm{~nm}$ ) of the fluorescence maximum observed with an increase in the concentration of quencher is suggestive for the formation of aggregates, generally acknowledged as new ground-state species. Usually, their formation is coming with a red shift or/and generation of a new low-energy peak in the emission spectra, presumably due to a lowering in quantum efficiency of photoluminescence. ${ }^{26}$ Another probable explanation may arise from dynamics of the interactions among metal ion and triazene group to promote to metal-bound triazene polymeric complexes.

To conclude and to prove once again that triazene chromophore is responsible for fluorescence maxima of the triazene copolymers, $\mathrm{CuBr}_{2}$ was used to analyze its quenching effect on the solution of TCP-1 after its exposure with UV irradiation for $10 \mathrm{~min}$. Even if a faster fluorescence quenching was previously observed for $\mathrm{CuBr}_{2}$ (Figure 7) on the irradiated TCP-1 solution, the quenching process in this case was completely inefficient.

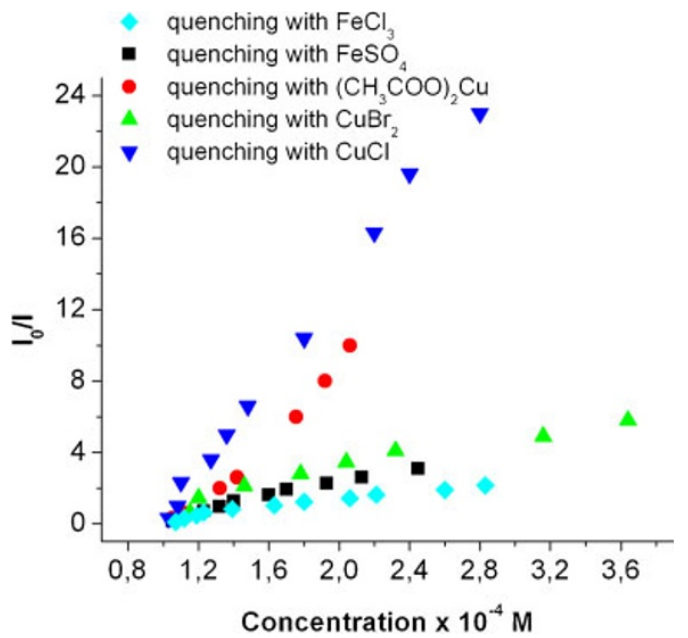

Figure 10. Stern-Volmer plots of TCP-1 copolymer as a function of different quencher concentrations.

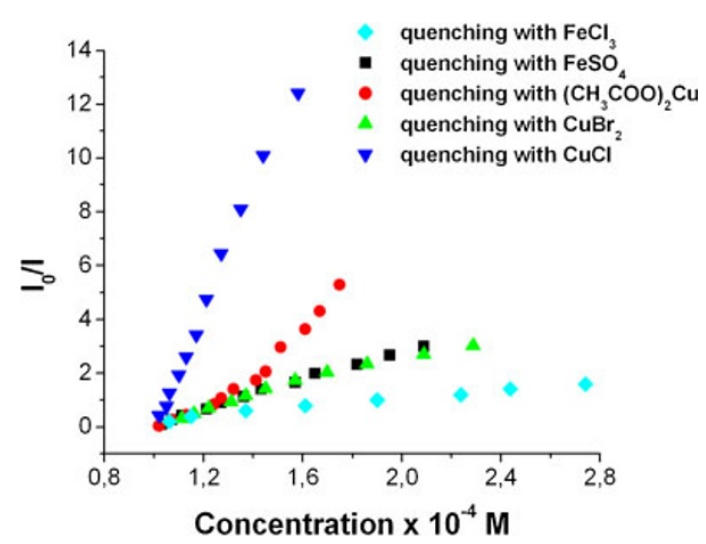

Figure 11. Stern-Volmer plots of TCP-2 copolyacrylate as a function of different quencher concentrations.

Starting from these considerations it is important to examine the mechanism of the quenching process. That's way the emission spectra were analyzed carefully using Stern-Volmer equation:

$$
I_{0} / I=1+K_{\mathrm{SV}}[Q]
$$

where $I_{0}$ and $I$ are the fluorescence intensities in the absence and in the presence of the metal ions, respectively, $K_{\mathrm{SV}}$ is the Stern-Volmer constant and $[Q]$ is the concentration of the quencher. The kinetic scheme gives linear curves obtained for a plot $I_{0} / I$ versus $[Q]$ for both systems. A representative SternVolmer plot for TCP-1 copolymer is shown in Figure 10.

Furthermore, Figure 11 displays that the Stern-Volmer plot for all quenchers $\left(\mathrm{FeCl}_{3}, \mathrm{FeSO}_{4},\left(\mathrm{CH}_{3} \mathrm{COO}\right)_{2} \mathrm{Cu}, \mathrm{CuBr}, \mathrm{CuCl}\right)$ utilized in the case of TCP-2 triazene copolyacrylate, where linear portions of the plot of $I_{0} / I$ versus $[Q]$ is also indicated. Apparent Stern-Volmer constants decrease in the order: $\mathrm{Fe}^{3+}>\mathrm{Fe}^{2+}>\mathrm{Cu}^{2+}>\mathrm{Cu}^{+}$and these results directly reflect the relative sensitivity of the method for the above metal ions. The quenching is pronounced in the case of $\mathrm{Fe}^{2+}$ and $\mathrm{Cu}^{2+}$ 
$\left(\mathrm{CuBr}_{2}\right.$ and $\left.\left(\mathrm{CH}_{3} \mathrm{COO}\right)_{2} \mathrm{Cu}\right)$ and the minimum quenching is observed for $\mathrm{Cu}^{+}$.

All the observed quenching efficiencies of the metal ions were found to be relatively similar to those reported with other fluorophores. ${ }^{27,28}$

The ability of transition metal cations $\left(\mathrm{Fe}^{3+}, \mathrm{Fe}^{2}, \mathrm{Cu}^{2+}\right.$ and $\mathrm{Cu}^{+}$) to quench the fluorescence of triazene polymers (TCP-1 and TCP-2) has been explained on the basis of energy transfer processes. Energy transfer quenching can occur when the energy of the triazene chromophore excited state is larger than the excited-state energy of the quencher and furthermore, the electronic motions of the two species are coupled, involving $\pi$ stacking formation. ${ }^{12}$ The efficiency of energy transfer, however, would be a function of the overlap and efficiency of this $\pi$-stacking process. Generally, energy transfer can take place by two most important transfer mechanisms: electron-exchange (Dexter's electron exchange mechanism) and dipole-dipole interaction (Förster's mechanism). In the electron-exchange mechanism, the donor and the acceptor approach so close to each other that the electron exchange happens very quickly. So, the donor is returning to the ground state and the acceptor is being raised to the excited sate. Energy transfer by dipoledipole mechanism operates by Coulombic resonance interactions, in which the oscillating electron of the excited state donor are coupled to those of the acceptor by an induced dipole interaction. $^{12,29}$

In the light of these considerations, the $d$ levels of lowenergy of transition metal ions play an important role in the quenching of the triazene fluorescence via the energy transfer, too. For example, a faster fluorescence quenching can be observed for $\mathrm{Fe}^{3+}\left(d^{5}\right)$, which can be attributed to a major efficiency of energy transfer between the triazene excited-state and metal ion and to the stability of the half-filled shell of $d^{5}$ metal ion also. Moreover, $\mathrm{Cu}^{2+}$ is well known as an excellent quencher because it is good electron "hunter" on account of its electronic structure $\left(d^{9}\right)$, and can easily introduces accessible low energy levels, which are capable of quenching the fluorescent excited states of the molecules. ${ }^{5}$

Stern Volmer plots for all quenchers $\left(\mathrm{FeCl}_{3}, \mathrm{FeSO}_{4}\right.$, $\left.\left(\mathrm{CH}_{3} \mathrm{COO}\right)_{2} \mathrm{Cu}, \mathrm{CuBr}_{2}, \mathrm{CuCl}\right)$ present data that are nearly collinear, indicating the involvement of only one quenching mechanism (energy transfer of Dexter type) and pointing a pure dynamic nature of this process. All these observation clearly suggests that the quenching influence of the transition metal ions need to be given special consideration for designing efficient triazene fluorosensors.

\section{CONCLUSIONS}

This work shows that the triazene copolyacrylates present emissive properties at excitation with $320 \mathrm{~nm}$, both in DMF solution and polymeric films, in the latter a bathochromic shift $(25 \mathrm{~nm})$ of the fluorescence maxima indicating the formation of aggregates. The results obtained during UV irradiation and excitation of the triazene groups in DMF solution sustain that that products appeared in the system by a recombination of phenyl/methoxy-phenyl diazenyl radicals emit fluorescence with a high quantum yield. It was demonstrated that the quenching of triazene fluorescence by metal ions $\left(\mathrm{Fe}^{+3}>\right.$ $\mathrm{Fe}^{+2}>\mathrm{Cu}^{+2}>\mathrm{Cu}^{+1}$ ) occurred according to Stern Volmer plots, and the quenching mechanism for triazene copolymers can be represented through a energy transfer process of Dexter type. The photophysical investigations revealed that such photopolymers could function as fluorescent chemosensors for some metal ions.

Acknowledgment. The authors acknowledge the financial support of the Ministry of Research and Education through a project from the National Research Program (Nr. 78/1/ 10.2007-PNII 2007).

Received: January 16, 2009

Accepted: May 10, 2009

Published: July 1, 2009

\section{REFERENCES}

1. L. Prodi, F. Bolletta, M. Montalti, and N. Zaccheroni, Eur. J. Inorg. Chem., 3, 455 (1999).

2. H. Ikeda, M. Nakamura, N. Ise, N. Oguma, A. Nakamura, T. Ikeda, F. Toda, and A. Ueno, J. Am. Chem. Soc., 118, 10980 (1996).

3. J.-M. Lehn, in "Supramolecular Chemistry: Concepts and Perspectives," Wiley-VCH, Weinheim, 1995.

4. K. Nishiwaki, A. Taga, M. Jamaya, Y. Morita, Y. Suzuki, S. Honda, and K. Matsuo, Chem. Lett., 35, 1418 (2006).

5. C. H. Kwon, J. H. Lee, and H. L. Kim, Bull. Korean Chem. Soc., 28 , 1485 (2007).

6. R. Kuwano, K. Uchida, and Y. Ito, Org. Lett., 5, 2177 (2003).

7. E. C. Buruiana, T. Buruiana, and L. Hahui, J. Photochem. Photobiol., A, 189, 65 (2007).

8. E. C. Buruiana, T. Buruiana, M. Zamfir, V. Pohoata, and D. Donescu, Des. Monomers Polym., 10, 347 (2007).

9. E. C. Buruiana, M. Zamfir, and T. Buruiana, J. Polym. Sci., Part A: Polym. Chem., 46, 3774 (2008).

10. E. C. Buruiana, M. Zamfir, and T. Buruiana, Eur. Polym. J., 43, 4316 (2007).

11. E. C. Buruiana, T. Buruiana, G. Strat, and M. Strat, J. Polym. Sci., Part A: Polym. Chem., 40, 1918 (2002).

12. E. C. Buruiana, M. Olaru, and B. C. Simionescu, Eur. Polym. J., 43, 1359 (2007).

13. K. Morigaki, H. Schönherr, C. W. Frank, and W. Knoll, Langmuir, 19, 6994 (2003).

14. C. A. Rouzer, M. Sabourin, T. L. Skinner, E. J. Thompson, T. O. Wood, G. N. Chmurny, J. R. Klose, J. M. Roman, R. H. Smith, and C. J. Michejda, Chem. Res. Toxicol., 9, 172 (1996).

15. A. Natansohn and P. Rochon, Chem. Rev., 102, 4139 (2002).

16. T. Lippert, M. Hauer, C. R. Phipps, and A. Wokaun, Appl. Phys. A: Mater. Sci. Process., 77, 259 (2003).

17. T. Lippert and J. T. Dickinson, Chem. Rev., 103, 453 (2003).

18. R. Fardel, M. Nagel, F. Nüesch, T. Lippert, and A. Wokaun, Appl. Phys. Lett., 91, 061103 (2007).

19. E. C. Buruiana, L. Hahui, T. Buruiana, L. Urech, and T. Lippert, J. Photochem. Photobiol., A, 195, 337 (2008).

20. E. C. Buruiana, T. Buruiana, L. Hahui, T. Lippert, L. Urech, and A. Wokaun, J. Polym. Sci., Part A: Polym. Chem., 44, 5271 (2006).

21. O. Nuyken, C. Scherer, A. Baindl, A. Brenner, U. Dahn, R. Gartner, S. Kaiser-Rohrich, R. Kollefrath, P. Matusche, and B. Voit, Prog. Polym. Sci., 22, 93 (1997).

22. P. Gupta, S. R. Trenor, T. E. Long, and G. L. Wilkes, Macro- 
molecules, 37, 9211 (2004).

23. Y. Posokhov, M. Kus, H. Biner, M. K. Gumus, F. T. Tugcu, E. Aydemir, S. Kaban, and S. Icli, J. Photochem. Photobiol., A, 161, 247 (2004).

24. H. R. Park, J. J. Seo, S. C. Shin, H. S. Lee, and K. M. Bark, Bull. Korean Chem. Soc., 28, 1573 (2007).

25. H. Cai, X.-H. He, D.-Y. Zheng, J. Qiu, Z.-C. Li, and F.-M. Li,
J. Polym. Sci., Part A: Polym. Chem., 34, 1245 (1996).

26. K. Y. Peng and S. A. Chen, J. Phys. Chem. B, 109, 9368 (2005).

27. A. W. Varnes, R. B. Dodson, and E. L. Wehry, J. Am. Chem. Soc., 94, 946 (1972)

28. J. A. Kemlo and T. M. Shepherd, Chem. Phys. Lett., 47, 158 (1977).

29. D. R. Worrall, I. Kirkpatrick, and S. L. Williams, Photochem. Photobiol. Sci., 1, 896 (2002). 